\title{
EVALUASI JARAK AMAN ANTARA STRUKTUR SRPM TINGGI DENGAN STRUKTUR SRPM DISEBELAHNYA TERHADAP GEMPA
}

\author{
Ade Faisal1, Tondi Amirsyah Putera ${ }^{2}$, Mariden Purba ${ }^{3}$ \\ 1,2,Dosen Pengajar Program Studi Teknik Sipil, Fakultas Teknik, UMSU, Medan \\ ${ }^{3}$ PT. Kereta Api Indonesia, Divisi Regional I Sumatera Utara, Medan \\ 1Surel : adef@umsu.ac.id \\ Diterima : 16 Mei 2018; Disetujui : 28 Mei 2018
}

\begin{abstract}
ABSTRAK
Pembangunan gedung-gedung tinggi menjadi salah satu alternatif yang di pilih karena keterbatasan dan mahalnya lahan diperkotaan sementara tingkat permintaan ruang untuk berbagai kegiatan semakin tinggi. Hal ini menyebabkan gedung-gedung bertingkat sering dibangun saling berdekatan satu dengan yang lainnya. Benturan dapat terjadi pada dua bangunan gedung bertingkat yang bersebelahan apabila jarak antara dua bangunan lebih kecil dari simpangan maksimum yang terjadi akibat beban gempa. Studi ini bertujuan untuk mencari jarak aman antara dua bangunan tinggi yang bersebelahan. Gedung yang direncanakan 2 model menggunakan SRPM dengan material beton bertulang yang terletak di kota Medan dengan kondisi tanah sedang. Model pertama (Model 1) direncanakan memiliki tinggi 28,5 meter terdiri dari 8 lantai, sedangkan Model kedua (Model 2) direncanakan memiliki tinggi 35,5 meter terdiri dari 10 lantai. Analisa yang digunakan pada studi ini yaitu analisis dinamik riwayat waktu. Nilai simpangan yang terjadi pada gedung 8 lantai (Model 1) untuk arah x sebesar 80,87 mm dan untuk arah y sebesar 79,35 mm. Simpangan yang terjadi pada gedung 10 lantai (Model 2) untuk arah x sebesar 113,33 mm dan untuk arah y sebesar 112,39 mm. Hasil analisa yang dilakukan menunjukkan jarak aman antara gedung 8 lantai dengan gedung 10 lantai adalah sebesar 2,1 meter, sedangkan jarak aman antara gedung 10 lantai dengan gedung 10 lantai adalah sebesar 2,2 meter.
\end{abstract}

Kata Kunci : Analisis Riwayat Waktu, Benturan Antar Gedung, Jarak Antar Gedung, Simpangan

\begin{abstract}
The construction of tall buildings became one of alternative that was chosen because of the urban land limitations and the cost. At the same time the space demand for various urban activities is increased. It is caused the high-rise buildings are often built very close to one another. The collision can be occurred if two adjacent building if the distance between the two building is smaller than the maximum drift caused by the earthquake action. This study aims to plan a safe distance between two adjacent high-rise buildings. The planned building two models using Moment Resisting Frame with reinforced concrete material that is located in the city Medan with moderate soil conditions. The first model (Model 1) has a height of 28.5 meters is planned consists of 8 floors, while the second model (Model 2) planned to have a height of 35.5 meters consists of 10 floors. The analysis used in this study is the analysis of dynamic time history. The displacement value which occurred on 8 storey building (Model 1) to the $x$ direction by $80.87 \mathrm{~mm}$ and for the y direction by $79.35 \mathrm{~mm}$. The displacement occurs in the building 10 floors (Model 2) to the $x$ direction of $113.33 \mathrm{~mm}$ and for the $y$ direction of $112.39 \mathrm{~mm}$. The results of analysis indicate that the safe distance between 8 storey building with 10 floors of the building is 2.1 meters, while the safe distance between buildings 10 floors with 10 storey building is 2.2 meters.
\end{abstract}

Keywords: Time History Analysis, Clash Between Buildings, Distance Between Buildings, Deviation 


\section{Pendahuluan}

Bangunan bertingkat banyak ditemui didaerah perkotaan yang memiliki jumlah penduduk yang sangat padat seperti dikotakota besar di Indonesia. Pembangunan gedunggedung tinggi menjadi salah satu alternatif yang banyak dipilih pada saat ini karena keterbatasan dan mahalnya lahan diperkotaan sementara tingkat permintaan ruang untuk berbagai kegiatan semakin tinggi.

Indonesia merupakan salah satu negara yang rawan terhadap bencana gempa bumi. Hal ini disebabkan karena lokasi Indonesia yang terletak pada pertemuan empat lempeng tektonik utama yaitu Lempeng Euresia, IndoAustralia, Pasifik, dan Filipina. Dalam kurun waktu 10 tahun terakhir Indonesia tercatat mengalami beberapa kejadian gempa besar yaitu gempa Aceh tahun 2004, gempa Nias tahun 2005, gempa Yogyakarta tahun 2006 dan gempa Padang pada tahun 2009. Gempa tersebut menyebabkan kerusakan infrastruktur yang cukup parah dan menelan korban jiwa dan harta benda dalam jumlah yang sangat besar. Hal ini disebabkan karena saat gempa terjadi gedung mengalami kegagalan struktur karena terjadinya simpangan horizontal terhadap gedung dan telah melampaui syarat aman yang telah ditetapkan oleh peraturan SNI 03-1726-2002. Oleh sebab itu, pemerintah serta ilmuwan terkait pada bidang kegempaan merevisi standar perencanaan SNI 03-1726-2002 menjadi SNI 1726:2012.

Kebutuhan terhadap ruang yang semakin meningkat serta terbatasnya ketersediaan lahan menyebabkan gedung-gedung bertingkat sering dibangun saling berdekatan satu dengan yang lainnya. Apabila terjadi gempa bumi maka kedua bangunan yang berdekatan tersebut akan bergoyang menurut pola goyangan yang berbeda. Pada keadaan tersebut kedua bangunan dapat mengalami benturan (pounding), yaitu bangunan yang satu menghantam bangunan sebelahnya. Benturan tersebut dapat mengakibatkan kerusakan atau bahkan mengalami kegagalan struktur. Oleh sebab itu, dalam mendesain bangunan tinggi yang berdekatan haruslah dicari jarak yang aman agar tidak terjadi benturan.

Berdasarkan hal tersebut diatas, maka Penulisan penelitian ini adalah untuk menganalisa jarak aman antara bangunan tinggi yang bersebelahan terhadap bahaya getaran gempa.

\section{Kajian Pustaka}

\subsection{Jarak Antar Bangunan}

Pada bangunan bertingkat banyak yang saling berdekatan, maka jarak antar bangunan harus diperhitungkan dengan teliti dengan angka keamanan yang cukup. Pada kondisi bangunan tinggi yang berdekatan kemungkinan mempunyai kekakuan yang berbeda-beda dan pada saat terjadi gempa bumi, maka kedua bangunan akan bergoyang menurut pola goyangan (mode) yang berbeda. Kondisi tersebut bisa mengakibatkan terjadinya benturan antara dua gedung tinggi yang berdekatan

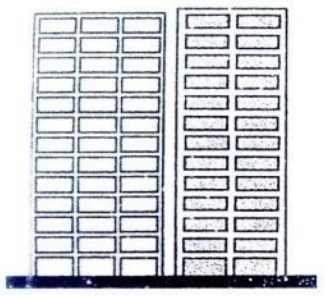

(a)

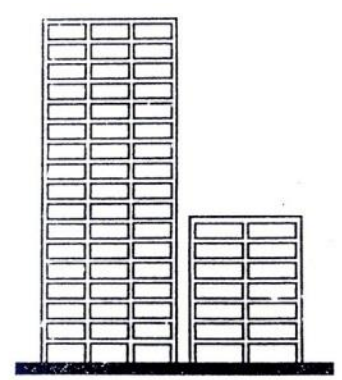

(b)

\section{Gambar 1. Jarak Antara Dua Bangunan}

\subsection{Efek Benturan}

Pada bangunan bertingkat banyak, respon struktur terhadap beban lateral yang diakibatkan oleh beban angin dan beban gempa menjadi sangat besar. Jika suatu struktur bertingkat tinggi dibebani beban lateral $(\mathrm{F}(\mathrm{t}))$ seperti beban gempa, maka struktur akan mengalami deformasi berupa simpangan lateral $(\Delta)$. Simpangan lateral yang berlebihan dapat menimbulkan ketidakstabilan lateral pada struktur dan dapat mengalami keruntuhan.

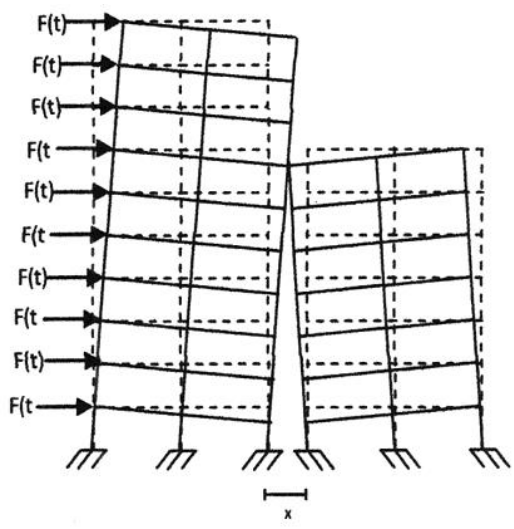

Gambar 2. Benturan Dua Gedung Yang Bersebelahan 


\section{Evaluasi Jarak Aman Antara Struktur Srpm Tinggi Dengan Struktur Srpm Disebelahnya Terhadap Gempa}

Simpangan lateral yang berlebihan juga dapat menimbulkan benturan pada dua struktur tinggi yang bersebelahan. Apabila terjadi benturan dapat mengakibatkan kerusakan pada struktur, dimana diantara komponen struktur atau bahkan struktur secara keseluruhan kehilangan kemampuan menahan beban yang dipikulnya.

\subsection{Jarak Pemisah Bangunan Dan Kontrol Simpangan}

Dalam hal ini simpangan lateral sangat perlu untuk diperhitungkan dalam perencanaan struktur bertingkat banyak yang bersebelahan untuk menentukan jarak pemisah yang cukup aman dari kedua bangunan tinggi yang bersebelahan. Untuk menghindari terjadinya pelelehan baja dan peretakan beton yang berlebihan, disamping untuk mencegah kerusakan non-struktur dan ketidaknyamanan penghuni perlu dihindari perilaku simpangan yang berlebihan. Hubungan antara simpangan lateral dan potensi kerusakan bangunan sangat bervariasi dan tergantung pada detail dari struktur struktur bangunan tersebut.

Berdasarkan SNI 1726:2012 Pasal 7.12.3, dimana semua bagian struktur harus didesain dan dibangun untuk bekerja sebagai satu kesatuan yang terintegrasi dalam menahan gaya-gaya gempa kecuali jika dipisahkan secara struktural dengan jarak yang cukup memadai untuk menghindari benturan yang merusak.

Pemisahan harus dapat mengakomodasi terjadinya perpindahan respons inelastik maksimum $\left(\delta_{m}\right) . \delta_{m}$ harus dihitung pada lokasi kritis dengan mempertimbangkan perpindahan translasi maupun rotasi pada struktur, termasuk pembesaran torsi (bila ada), dengan menggunakan Persamaan (1) berikut ini.

$$
\delta_{M}=\frac{C_{d} \cdot \delta_{\max }}{I_{e}}
$$

Dimana: $\delta_{\max }=$ Perpindahan Elastik maksimum pada lokasi kritis

Struktur-struktur bangunan yang bersebelahan harus dipisahkan minimal sebesar $\delta_{M T}$, yang dihitung dari Pers. 2 berikut ini.

$$
\delta_{M T}=\sqrt{\left(\delta_{M 1}\right)^{2}+\left(\delta_{M 2}\right)^{2}}
$$

dimana:

$$
\begin{aligned}
\delta_{M 1} \text { dan } \delta_{M 2} & =\text { Perpindahan respons } \\
& \text { inelastik maksimum pada } \\
& \text { struktur-strukturbangunan } \\
& \text { yang bersebelahan di tepi- } \\
& \text { tepi yang berdekatan. }
\end{aligned}
$$

Struktur bangunan harus diposisikan berjarak paling tidak sejauh $\delta_{M}$ dari garis batas kepemilikan tanah.

\section{Metodologi}

Dalam penelitian ini terdapat 2 gedung yang menjadi studi, yaitu gedung 8 lantai (Model 1) dan 10 lantai (Model 2). Struktur gedung adalah portal beton yang dimodelkan sebagai element frame 3 dimensi (3D) pada ETABS dengan mengacu pada standar gempa berdasarkan SNI 1726:2012 dan perencanaan struktur beton berdasarkan SNI 03-2847-2002 dan dimensi struktur adalah simetris segiempat.

\subsection{Model Struktur}

Model gedung yang pertama memiliki jumlah 8 tingkat dan model kedua memiliki jumlah 10 tingkat, untuk denah kedua model memiliki dimensi yang sama yaitu panjang denah $\operatorname{arah} \mathrm{x}=20 \mathrm{~m}$ dan $\operatorname{arah} \mathrm{y}=18 \mathrm{~m}$, memiliki tinggi untuk lantai $1=4 \mathrm{~m}$ dan lantai seterusnya $3,5 \mathrm{~m}$. Untuk pemodelan dari struktur gedung 8 lantai dan 10 lantai tersebut dapat dilihat pada Gambar 3 dibawah ini.

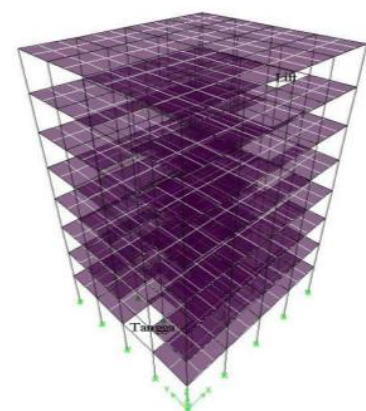

(a)

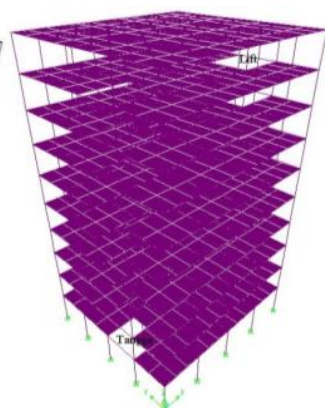

(b)
Gambar 3. Model Struktur

\subsection{Data Rencana Struktur}

- Jenis portal struktur gedung beton bertulang

- Bangunan berfungsi sebagai perkantoran

- Lokasi bangunan berada di kota Medan dengan kondisi tanah sedang 
- Gedung didesain berdasarkan SRPMM (Struktur Rangka Pemikul Momen Menengah).

- Material yang digunakan untuk kuat tekan beton adalah $f^{\prime} c 25 \mathrm{MPa}$ dengan poisson's ratio beton adalah 0,2 .

- Mutu baja tulangan utama direncanakan $f y=400 \mathrm{Mpa}$

\subsection{Ukuran dan Penampang Struktur}

Adapun perencanaan dimensi balok dan kolom untuk model 1 dapat dilihat pada Tabel 1 dan model 2 diperlihatkan pada Tabel 2 diawah ini.

Tabel 1. Dimensi Penampang Balok Dan Kolom Model 1.

\begin{tabular}{ccl}
\hline Notasi & $\begin{array}{c}\text { b } \mathbf{~ h} \\
(\mathbf{c m})\end{array}$ & \multicolumn{1}{c}{ Keterangan } \\
\hline B1-50/75 & $50 \times 75$ & Balok induk lantai 1-4 \\
B2-40/70 & $40 \times 70$ & Balok induk lantai 5-7 \\
B3-30/60 & $30 \times 60$ & Balok induk lantai 8 \\
K1-75/75 & $75 \times 75$ & Kolom lantai 1 \\
K2-70/75 & $70 \times 75$ & Kolom lantai 2-4 \\
K3-70/70 & $70 \times 70$ & Kolom lantai 5-7 \\
K4-60/60 & $60 \times 60$ & Kolom lantai 8 \\
\hline
\end{tabular}

Tabel 2. Dimensi Penampang Balok Dan Kolom Model 2.

\begin{tabular}{ccl}
\hline Notasi & $\begin{array}{c}\mathbf{b} \mathbf{x h} \\
(\mathbf{c m})\end{array}$ & \multicolumn{1}{c}{ Keterangan } \\
\hline B1-50/85 & $50 \times 85$ & Balok induk lantai 1-3 \\
B2-48/80 & $48 \times 80$ & Balok induk lantai 4-6 \\
B3-40/70 & $40 \times 70$ & Balok induk lantai 7-9 \\
B4-30/50 & $30 \times 50$ & Balok induk lantai 10 \\
K1-75/80 & $75 \times 80$ & Kolom lantai 1 \\
K2-70/75 & $70 \times 75$ & Kolom lantai 2-7 \\
K3-70/70 & $70 \times 70$ & Kolom lantai 8-10
\end{tabular}

\subsection{Nilai Waktu Getar Alami}

Berdasarkan peraturan SNI 1726:2012, periode fundamental (T) yang digunakan memiliki batas maksimum dan batas minimum, sedangkan konstanta yang diperlukan adalam menentukan waktu getar alami diperlukan $C_{r}=$ 0,$0466 ; x=0,9$ dan $C_{u}=1,4$
Tabel 3. Pengecekan T Berdasarkan Pembatasan Waktu Getar Alami Fundamental Model 1 Berdasarkan SNI 1726:2012.

\begin{tabular}{cccccc}
\hline Arah & $\begin{array}{c}\text { Ta min } \\
= \\
\text { Cr*hnx }\end{array}$ & $\begin{array}{c}\text { Ta maks } \\
=\mathrm{Cu}^{*} \mathrm{Ta} \\
\text { min }\end{array}$ & $\mathrm{T}$ & $\begin{array}{c}\text { Cek } \\
\text { min }\end{array}$ & $\begin{array}{c}\text { Cek } \\
\text { maks }\end{array}$ \\
\hline $\mathrm{X}$ & 0.95004 & 1.33006 & 1.3088 & OK & OK \\
$\mathrm{Y}$ & 0.95004 & 1.33006 & 1.2819 & OK & OK \\
\hline
\end{tabular}

Tabel 4. Pengecekan T Berdasarkan Pembatasan Waktu Getar Alami Fundamental Model 2 Berdasarkan SNI 1726:2012

\begin{tabular}{cccccc}
\hline Arah & $\begin{array}{c}\text { Ta min } \\
= \\
\text { Cr*hnx }\end{array}$ & $\begin{array}{c}\text { Ta maks } \\
=\mathrm{Cu}^{*} \mathrm{Ta} \\
\text { min }\end{array}$ & T & $\begin{array}{c}\text { Cek } \\
\text { min }\end{array}$ & $\begin{array}{c}\text { Cek } \\
\text { maks }\end{array}$ \\
\hline $\mathrm{X}$ & 1.1576 & 1.6207 & 1.5250 & OK & OK \\
$\mathrm{Y}$ & 0.95004 & 1.6207 & 1.5069 & OK & OK \\
\hline
\end{tabular}

\subsection{Gaya Gempa Dasar}

Dalam analisa model struktur ini menggunakan analisis time history. Adapun langkah-langkah yang dilakukan dalam analisis time history berdasarkan SNI 1726:2012 sebagai berikut:

1) Menentukan respon spektrum berdasarkan SNI 1726:2012 untuk kota Medan dengan jenis tanah sedang.

2) Copy data respon spektrum kedalam Notepad.

3) Mencari data rekaman gempa pada web : http://peer.berkeley.edu/nga/ dengan cara mengupload data respon spektrum yang telah dicopy ke dalam Notepad.

4) Copy data rekaman kedalam Notepad.

5) Skalakan RSA (Respon Spektra Acceleration) pada Time History Cases dalam program ETABS dengan mengacu pada periode fundamental yang diperoleh dari ETABS.

\section{$4 \quad$ Hasil dan Pembahasan}

4.1 Perbandingan Analisis Model 1 dan Model 2 untuk Gaya Geser Dalam

Dari hasil analisis riwayat waktu yang menggunakan program ETABS diperoleh nilai gaya geser dasar $(V)$ berdasarkan SNI 1726:2012 yang disajikan pada Tabel 5 untuk gedung Model 1 dan Tabel 6 untuk gedung Model 2.

Tabel 5. Gaya Geser Hasil Analisa Riwayat Waktu Berdasarkan SNI 1726:2012 Model 1.

\begin{tabular}{ccc}
\hline Gempa & Arah x $(\mathrm{Kg})$ & Arah y $(\mathrm{Kg})$ \\
\hline Arah X & 248132,78 & - \\
Arah Y & - & 229492,6 \\
\hline
\end{tabular}




\section{Evaluasi Jarak Aman Antara Struktur Srpm Tinggi Dengan Struktur Srpm Disebelahnya Terhadap Gempa}

Tabel 6. Gaya Geser Hasil Analisa Riwayat Waktu Berdasarkan SNI 1726:2012 Model 2.

\begin{tabular}{ccc}
\hline Gempa & Arah x $(\mathrm{Kg})$ & Arah y $(\mathrm{Kg})$ \\
\hline Arah X & 248414,18 & - \\
Arah Y & - & 248413,86 \\
\hline
\end{tabular}

4.2 Perbandingan Analisis Model 1 dan Model 2 Untuk Nilai Simpangan Gedung

Berdasarkan SNI 1726:2012, simpangan antar lantai hanya ada kondisi kinerja batas ultimit saja. Simpangan tersebut di peroleh dari hasil output program ETABS akibat beban gempa dan beban gravitasi yang bekerja pada gedung tersebut yang dikombinasikan. Dan ditunjukkan pada Gambar 4,5,6 dan 7 dibawah ini.

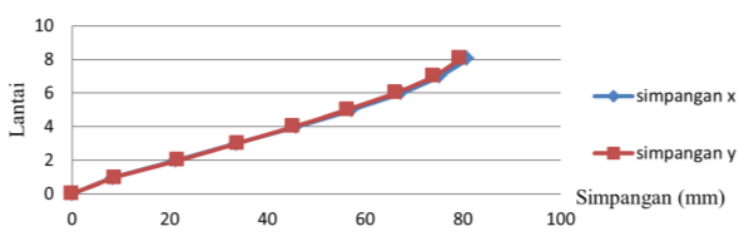

Gambar 4. Simpangan Arah X Dan Y Gedung Model 1

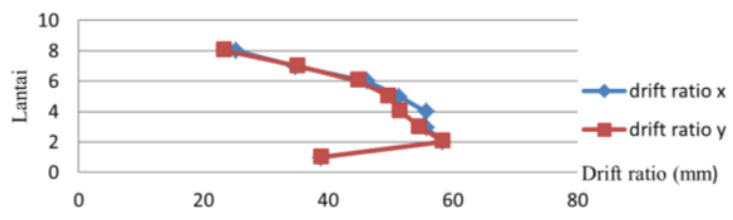

Gambar 5. Drift Ratio Arah X Dan Y Model 1

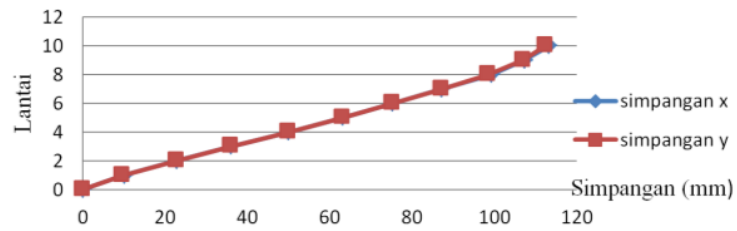

Gambar 6. Simpangan Arah X Dan Y Gedung Model 2

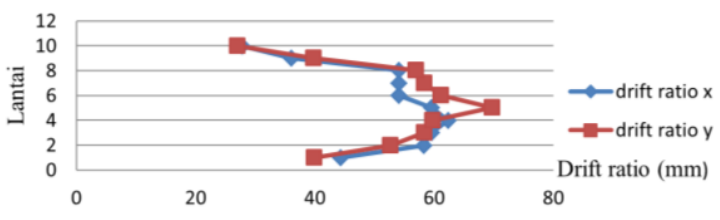

Gambar 7. Drift Ratio Arah X Dan Y Model 2
4.3 Jarak Aman Bangunan

4.3.1 Jarak Aman Antara Lantai 8 dengan Lantai 10

Untuk mengetahui berapa jarak yang diperlukan antara 8 lantai dan 10 lantai agar dua bangunan yang bersebelahan tidak saling berbenturan pada saat terjadi gempa dilakukan dengan bantuan program ETABS, yaitu mencoba jarak mulai dari 0,5 meter hingga didapat jarak yang aman dan gedung tidak mengalami benturan.

Tabel 7. Jarak Aman Gedung 8 Lantai Dengan Gedung 10 Lantai

\begin{tabular}{|c|c|c|c|c|c|c|c|c|c|c|c|c|}
\hline \multirow{2}{*}{\multicolumn{2}{|c|}{$\begin{array}{c}\text { Jarak } \\
(\mathrm{m})\end{array}$}} & \\
\hline & & 1 & 2 & 3 & 4 & 5 & 6 & 7 & 8 & 9 & 10 & $\begin{array}{ll}111 & 12 \\
\end{array}$ \\
\hline 0.5 & \multirow{5}{*}{$\begin{array}{l}\text { Lantai Yang } \\
\text { Berbenturar }\end{array}$} & $\begin{array}{c}8,7,6,5,5 \\
4,3\end{array}$ & . & $\begin{array}{c}2,3,4,5,5, \\
6,7,8\end{array}$ & $\begin{array}{l}3,4,5,6,6, \\
7,8\end{array}$ & - & $\begin{array}{c}2,3,4,5, \\
6,7,8\end{array}$ & $\begin{array}{c}2,3,4,5,5 \\
6\end{array}$ & . & $\begin{array}{c}\begin{array}{c}2,3,4,4,5 \\
6,8\end{array} \\
\end{array}$ & $1,2,3,4$ & $\begin{array}{r}1,2,3,4 \\
5,7,8\end{array}$ \\
\hline 1 & & $5,6,7,8$ & - & $\begin{array}{c}4,5,6,7, \\
8\end{array}$ & $5,6,7,8$ & . & $\begin{array}{l}4,5,6,7,7, \\
8\end{array}$ & $2,3,4,5$ & - & $3,4,5$ & $2,3,4$ & $\begin{array}{r}2,3,4,7 \\
8\end{array}$ \\
\hline 15 & & 7.8 & & $5,6,7,8$ & 7,8 & & $6,7,8$ & 4 & & & 3,4 & 3,8 \\
\hline 2 & & - & & 8 & & & 8 & & & & & 8 \\
\hline 21 & & - & & & & & & & & & & \\
\hline
\end{tabular}

Dari Tabel 7 terlihat, kondisi yang cukup aman antara gedung 8 lantai dan gedung 10 lantai yang cukup aman terlihat pada saat mencapai 2,1 m. Kondisi ini diukur dari as ke as gedung

\subsubsection{Jarak Aman Antara Lantai 10 dengan Lantai 10 \\ Untuk mengetahui jarak aman antara} gedung 10 lantai dengan 10 lantai memiliki langkah yang sama dengan cara mencari jarak aman antara gedung 8 lantai dengan 10 lantai.

Tabel 8. Jarak Aman Gedung 10 Lantai Dengan Gedung 10 Lantai

\begin{tabular}{|c|c|c|c|c|c|c|c|c|c|c|c|c|c|}
\hline \multirow{2}{*}{\multicolumn{2}{|c|}{$\begin{array}{l}\text { Jarak } \\
\text { (m) }\end{array}$}} & \multicolumn{11}{|c|}{ Mode } & \\
\hline & & 1 & 2 & & 4 & 5 & 6 & 7 & 8 & 9 & 10 & 11 & 12 \\
\hline \multirow{3}{*}{0,5} & \multirow{7}{*}{$\begin{array}{l}\text { Lantai Yang } \\
\text { Berbenturan }\end{array}$} & & $\begin{array}{l}2,3,4,5 \\
67.89\end{array}$ & & & $\begin{array}{l}2,3,4,5 \\
6,7.89\end{array}$ & $\begin{array}{l}3,4,4,6,6 \\
7.89,1\end{array}$ & $8,9,10$ & $\begin{array}{l}1,2,3,3,4, \\
67\end{array}$ & & & $\begin{array}{l}2.3,4,4,5 \\
689.1\end{array}$ & $\begin{array}{l}1,2,3,3,4 \\
5689\end{array}$ \\
\hline & & & $4,5,6,7$ & & & $5,67,8$ & $6,7,8,9$ & 9,1 & $2,3,4,5$, & . & $\therefore$ & $3,4,5,9$, & $2,3,4,5$, \\
\hline & & & $8,9,10$ & & $=$ & 9,10 & 10 & & & & & 10 & $6,9,10$ \\
\hline \multirow[t]{2}{*}{1,5} & & & $7,8,9,1$ & & & $8,9,10$ & $\mathbf{8 , 9 , 1 0}$ & 10 & $3,4,5$ & & & 10 & 10 \\
\hline & & & 9,1 & & & 9,1 & 9,1 & 10 & & & & 10 & 10 \\
\hline 21 & & & & & & & & 10 & & & & & \\
\hline 22 & & & & & & & & & & & & & \\
\hline
\end{tabular}

\section{Simpulan}

Berdasarkan analisis data dan pembahasan mengenai jarak aman dua bangunan tinggi yang bersebelahan terhadap getaran gempa, maka dapat diambil kesimpulan sebagai berikut:

1) Nilai simpangan gedung Model 1 untuk arah $x$ sebesar $80,87 \mathrm{~mm}$ dan arah $y$ sebesar 79,35 mm. Sedangkan nilai simpangan untuk gedung Model 2 lebih besar daripada gedung Model 1, yaitu arah $\mathrm{x}$ sebesar $113,33 \mathrm{~mm}$ dan arah $\mathrm{y}$ sebesar $112,39 \mathrm{~mm}$. 
2) Gedung tidak mengalami benturan pada jarak tertentu antara 8 lantai dan 10 lantai terjadi pada: Jarak $0,5 \mathrm{~m}$ pada mode $2,5,8,11$. Jarak $1 \mathrm{~m}$ pada mode $2,5,8,11$. Jarak $1,5 \mathrm{~m}$ pada mode $2,5,8,9,11$. Jarak $2 \mathrm{~m}$ pada mode $1,2,4,5,7,8,9,10,11$, dan antara 10 lantai dan 10 lantai gedung pada jarak tertentu tidak mengalami benturan terjadi pada: Jarak $0,5 \mathrm{~m}$ pada mode $1,3,4,9,10$. Jarak $1 \mathrm{~m}$ pada mode $1,3,4,9,10$. Jarak $1,5 \mathrm{~m}$ pada mode $1,3,4,9,10$. Jarak $2,1 \mathrm{~m}$ pada mode $1,2,3,4,5,6,8,9,10,11,12$.

3) Dari hasil analisa yang telah dilakukan, didapatkan jarak aman antara dua bangunan tinggi yang bersebelahan, yaitu:

- Jarak aman antara gedung 8 lantai (Model 1) dengan gedung 10 lantai (Model 2) sebesar 2,1 m.

- Jarak aman antara gedung 10 lantai (Model 2) dengan gedung 10 lantai (Model 2) sebesar 2,2 m.
Gempa Dengan Menggunakan SNI 031726-2002 dan SNI 1726:2012. Bandung: ITB.

Departemen Pekerjaan Umum. 1987, Pedoman Perencanaan Pembebanan Untuk Rumah dan Gedung, Jakarta: Yayasan Badan Penerbit PU.

Imran, I. dan Hendrik, F. 2009, Perencanaan Struktur Beton Bertulang Tahan Gempa Berdasarkan SNI 03-2847-2002. Bandung: ITB.

Khozin, N. dan Darmawan, S.A (2008) Perencanaan Struktur Gedung Apartemen Permata Berlian Jakarta. Laporan Tugas Akhir. Semarang: Program Studi Teknik Sipil, Universitas Diponegoro.

Pawirodikromo, W (2012), Seismologi Teknik dan Rekayasa Kegempaan. Yogyakarta: Pustaka Pelajar.

Wibowo, A.S (2011) Analisis Kinerja Struktur Pada Bangunan Bertingkat Tidak Beraturan Dengan Analisis Dinamik Menggunakan Metode Analisis Riwayat Waktu. Laporan Tugas Akhir. Surakarta: Program Studi Teknik Sipil, Universitas Sebelas Maret.

\section{Daftar Pustaka}

Akbar, Z (2013) Perencanaan Gedung Baru Fakultas Teknik Universitas Muhammadiyah Sumatera Utara Menggunakan Basement. Laporan Tugas Akhir. Medan: Program Studi Teknik Sipil, Universitas Muhammadiyah Sumatera Utara.

Badan Standarisasi Nasional. 2012, Tata Cara Perencanaan Ketahanan Gempa Untuk Struktur Bangunan Gedung dan Non Gedung SNI 1726:2012. Jakarta: Departemen Pekerjaan Umum.

Badan Standarisasi Nasional. 2002, Tata Cara Perhitungan Struktur Beton Untuk Bangunan Gedung SNI 03-2847-2002. Jakarta: Departemen Pekerjaan Umum.

Badan Standarisasi Nasional. 2013, Beban Minimum Untuk Perancangan Bangunan Gedung dan Struktur Lain SNI 1727:2013. Jakarta: Departemen Pekerjaan Umum.

Budiono, B. dan Supriatna, L. (2011) Studi Komparasi Desain Bangunan Tahan 